\title{
ВЛИЯНИЕ ЭЛЕКТРОМАГНИТНОГО ПЕРЕМЕШИВАНИЯ НА ТЕПЛООБМЕННЫЕ ПРОЦЕССЫ В КРИСТАЛЛИЗАТОРЕ МНЛЗ
}

\author{
${ }^{1}$ А.С. Эльдарханов, ${ }^{2}$ А.С. Нурадинов, ${ }^{2}$ Н.С. Уздиева, ${ }^{2}$ С.С.-С. Ахтаев
}

1 - Научный центр «Новейшие материалы и технологии», г. Москва, Россия 2 - Грозненский государственный нефтяной технический университет им. академика М.Д. Миллионщикова, г. Грозный, Россия

Исследовано влияние электромагнитного перемешивания жидкого металла в кристаллизаторе МНЛЗ на процессы тепло-и массобмена в нем. Показано, что при увеличении интенсивности электромагнитного перемешивания затвердевающего металла увеличивается отвод тепла от затвердевающего металла и уменьшается время его полного затвердевания,что позволяет увеличить скорость разливки.

Ключевые слова: металл, расплав, твердая фаза, промковш, теплоотбор, ликвидус, режимы охлаждения, скорость разливки.

Формирование непрерывнолитой заготовки в кристаллизаторе МНЛЗ неразрывно связано протекающими в нем тепло-массообменными процессами, от которых зависят важнейшие параметры формирования заготовок в кристаллизаторе МНЛЗ: количество отведенного от расплава тепла, масса образовавшейся твердой фазы и толщина корковой оболочки [1].

Об интенсивности протекания тепловых процессов, протекающих в кристаллизаторах МНЛЗ можно судить по величине удельного теплоотвода $q_{\kappa p}$. (тепло, отводимое от одного килограмма металла за время его пребывания в кристаллизаторе), который определяют из зависимости:

$$
q_{\kappa p}=\frac{Q_{\kappa p}}{m_{\kappa p}},
$$

где $m_{\kappa p}-$ масса находящейся в кристаллизаторе заготовки. 
На рисунках 1-3 показаны результаты расчетов для квадратной заготовки 130х130 мм.

Эти данные показывают, что несмотря на почти одинаковую скорость разливки на отдельных ручьях стали и одинаковый расход воды на охлаждение кристаллизаторе, удельный теплоотвод в кристаллизаторе на разных ручьях изменялась в заметных пределах. Следует отметить, что с увеличением температуры металла в промковше увеличивается теплоотбор в кристаллизаторе. Что свидетельствует о том, что в кристаллизаторе происходит значительное уменьшение теплоты перегрева жидкой фазы стали над температурой ликвидус.

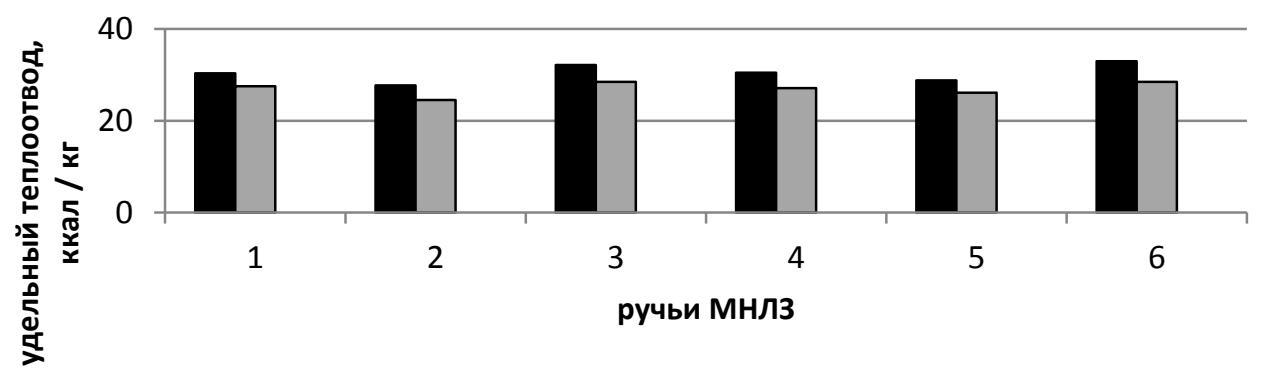

- Максимум $\square$ Минимум

Рис. 1. Максимальный и минимальный удельный теплоотвод в кристаллизаторе МНЛЗ на разных ручаях

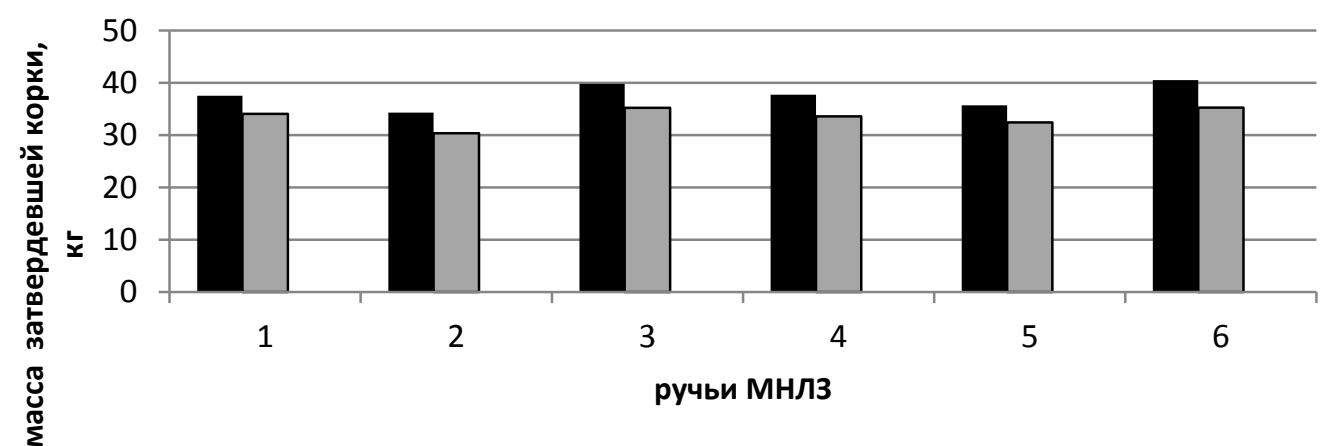

- Максимум $\square$ Минимум

Рис. 2. Максимальная и минимальная масса затвердевшего в кристаллизаторе МНЛЗ металла на разных ручаях 
Существенный разброс приведенных показателей обусловлен индивидуальными условиями формирования заготовок на каждом ручье МНЛЗ. Поэтому при назначении режимов охлаждения заготовки в зоне вторичного охлаждения необходимо учитывать состояние слитка на выходе из кристаллизатора [2].

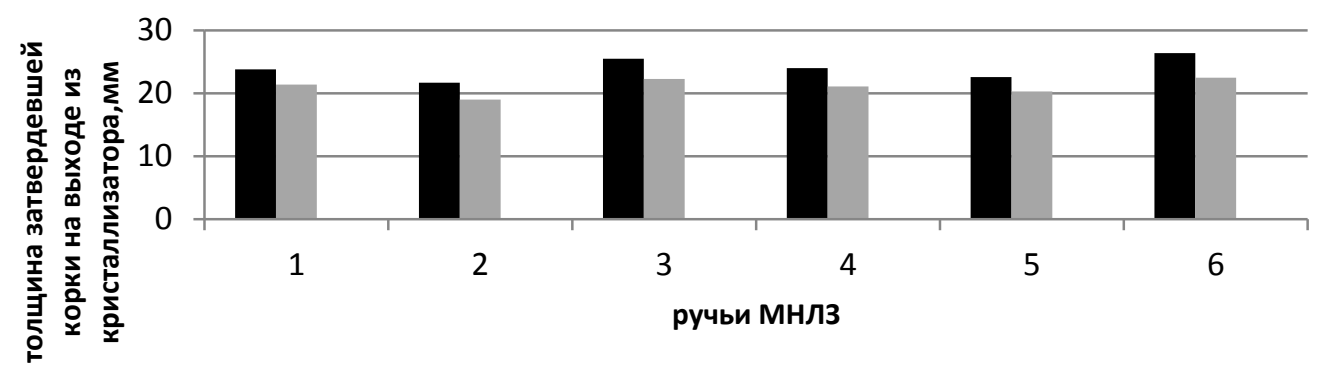

- Максимум Минимум

Рис. 3. Максимальная и минимальная толщина затвердевшей корки

на выходе из кристаллизатора МНЛЗ на разных ручаях

Используя паспортные данные плавок, толщину корки металла из кристаллизатора $(\delta)$ определяли, из известного выражения:

$$
\delta=k \sqrt{\tau},
$$

где $k$ - коэффициент затвердевания; $\tau$ - время затвердевания.

$$
\tau=\frac{h_{a}}{v}
$$

где $v$ - скорость разливки стали.

Для расчета величин, которые характеризуют формирование непрерывнолитой заготовки для каждой плавки, использовали данные АСУ ТП. В таблицах 1 и 2 приведены параметры литья и результаты расчетов для разных заготовок.

Параметры для квадратных заготовок, приведенные в таблице 1, показывают, что повышение интенсивности перемешивания расплавленного металла в кристаллизаторе 
позволяет увеличить интенсивность теплоотвода и массу затвердевшего металла [3]. Например, если силу тока электромагнитного перемешивания повысить от 182 до 443 А, то увеличиваются болем чем на $10 \%$ масса затвердевшей фазы и интенсивность теплоотвода.

Таблица 1 - Параметры формирования квадратных заготовок 130x130 мм

\begin{tabular}{|l|l|l|l|l|}
\hline \multicolumn{1}{|c|}{ № плавки } & \multicolumn{1}{c|}{$\mathbf{1}$} & \multicolumn{1}{c|}{$\mathbf{2}$} & \multicolumn{1}{c|}{$\mathbf{3}$} & \multicolumn{1}{c|}{$\mathbf{4}$} \\
\hline Скорость разливки, м/мин & 2,64 & 2,63 & 2,59 & 2,54 \\
\hline Сила тока перемешивания, пер. $A$ & 443 & 352 & 343 & 182 \\
\hline $\begin{array}{l}\text { Перепад температуры воды, } \\
\text { охлаждающей кристаллизатор на } \\
\text { входе и выходе из него, }{ }^{\circ} \mathrm{C}\end{array}$ & 5,7 & 5,5 & 5,3 & 5,05 \\
\hline $\begin{array}{l}\text { Удельный теплоотбор в } \\
\text { кристаллизаторе, ккал/кг }\end{array}$ & 32,39 & 31,37 & 30,69 & 29,82 \\
\hline Масса твердой фазы, кг & 40,12 & 38,86 & 38,03 & 36,95 \\
\hline
\end{tabular}

Параметры разливки по ручьям и результаты расчета для круглых заготовок приведены в таблице 2 .

Таблица 2 - Параметры формирования круглых заготовок Ø 150 мм

\begin{tabular}{|c|c|c|c|c|c|c|c|c|}
\hline \multirow{2}{*}{$\begin{array}{c}\text { № } \\
\text { II/II }\end{array}$} & \multirow{2}{*}{$\begin{array}{c}\text { Технические } \\
\text { параметры }\end{array}$} & \multicolumn{7}{|c|}{ № темплета } \\
\hline & & 1 & 2 & 3 & 4 & 5 & 6 & 7 \\
\hline 1 & $\begin{array}{l}\text { Температура стали в } \\
\text { промковше, }{ }^{\circ} \mathrm{C}\end{array}$ & 1544 & 1551 & 1551 & 1551 & 1551 & 1551 & 1551 \\
\hline 2 & $\begin{array}{l}\text { Скорость разливки, } \\
\text { м/мин }\end{array}$ & 2,35 & 2,15 & 2,10 & 2,20 & 2,15 & 2,10 & 2,20 \\
\hline 3 & $\begin{array}{lcc}\text { Масса стали } & \text { в } \\
\text { кристаллизаторе, кг } & \end{array}$ & 94,12 & 94,12 & 94,12 & 94,12 & 94,12 & 94,12 & 94,12 \\
\hline 4 & $\begin{array}{l}\text { Удельный теплоотвод } \\
\text { в } \quad \text { кристаллизаторе, } \\
\text { ккал }\end{array}$ & 24,90 & 24,02 & 27,79 & 27,00 & 23,51 & 27,59 & 26,51 \\
\hline 5 & $\begin{array}{l}\text { Расчетная масса } \\
\text { твердой фазы, кг }\end{array}$ & 23,26 & 21,88 & 25,08 & 24,73 & 21,39 & 25,31 & 24,27 \\
\hline 6 & $\begin{array}{l}\text { Расчетная толщина } \\
\text { корки на выходе из } \\
\text { кристаллизатора, мм }\end{array}$ & 14,9 & 13,9 & 16,1 & 15,9 & 13,6 & 16,3 & 15,5 \\
\hline 7 & $\begin{array}{l}\text { Расчетный } \\
\text { коэффициент }{ }^{3 a т в е р-} \\
\text { девания, см/мин }\end{array}$ & 2,66 & 2,40 & 2,71 & 2,94 & 2,34 & 2,76 & 2,72 \\
\hline
\end{tabular}




\begin{tabular}{|l|l|l|l|l|l|l|l|l|}
\hline 8 & $\begin{array}{l}\text { Полное время } \\
\text { затвердевания, мин }\end{array}$ & 7,96 & 9,78 & 7,17 & 6,51 & 10,20 & 7,38 & 7,61 \\
\hline 9 & Ток в ЭМП, А & 200 & 300 & 400 & 500 & 300 & 400 & 500 \\
\hline 10 & Частота тока, Гц & 3 & 3 & 6 & 6 & 3 & 3 & 3 \\
\hline 11 & № ручья & 2 & 5 & 2 & 2 & 5 & 2 & 2 \\
\hline
\end{tabular}

Полученные результаты (табл. 1 и 2) свидетельствуют о том, что изменение интенсивности перемешивания за счет увеличения величины тока от 200 до 500 А обеспечивает повышение интенсивности теплоотвода в кристаллизаторе [4]. Благодаря этому повышается коэффициент затвердевания и сокращается время полного затвердевания заготовок. Из представленных данных следует, что предпочтительными режимами перемешивания жидкой стали являются режимы перемешивания, достигаемые при токах 400-500 А в обмотке ЭМП. При этом количество образующейся в кристаллизаторе твердой фазы позволяет повысить скорость разливки заготовок на $10-15 \%$.

\section{Литература}

1. Eфимов B.A. Металлургические аспекты перемешивания сплавов в ковше и затвердевающем слитке // Процессы разливки и кристаллизации стали. Киев: ИПЛ АН УССР. 1991. С. 3-12.

2. Ефимов В. А. и др. Затвердевание и структура сплавов при интенсивном перемешивании // Стальной слиток. М.: Металлургия, 1986. С. 32-35.

3. Баранова В. Н., Якобше Р. Я., Найдек В. Л. $и$ др. Влияние газоимпульсного перемешивания жидкого металла на качество слитков и непрерывнолитых слябов // Процессы литья. 2010. № 6. С. 20-27.

4. Эльдарханов А.С., Нурадинов А С., Ахтаев С.С-С. О формировании непрерывнолитых заготовок при газоимпульсной и вибрационной обработке затвердевающего сплава // Металлургия машиностроения, 2015, № 2, C. 32-36. 